\title{
Steam Turbine Governor Design based on Pole Placement Technique
}

\author{
Firas M. Tuaimah \\ University of Baghdad \\ Baghdad, Iraq
}

\author{
Nihad M. Al-Rawi \\ University of Baghdad \\ Baghdad, Iraq
}

\author{
Waleed A. Mahmoud \\ University of Baghdad \\ Baghdad, Iraq
}

\begin{abstract}
This paper presents a computational methodology to design a steam turbine governor based on pole placement technique to control the turbine speed. The effectiveness of the proposed control action is demonstrated through some computer simulations on a Single-Machine Infinite- Bus (SMIB) power system.

To accommodate stability requirements, a mathematical model for the turbine was derived based on state space formulation. Results obtained shows that adopting such a controller enhanced the steady state and transient stability.
\end{abstract}

\section{Keywords}

Steam turbine, governor modeling, pole placement.

\section{INTRODUCTION}

The prime sources of electrical energy supplied by utilities are the kinetic energy of water and the thermal energy derived from fossil fuels and nuclear fission. The turbines convert these sources of energy into mechanical energy that is, in turn converted to electrical energy by the synchronous generator. The turbine governing system provide a means of controlling power and frequency, a function commonly referred to as load-frequency control or automatic generation control (AGC). Figure 1 portrays the functional relationship between the basic elements associated with power generation and control [1, 2 \& 3]

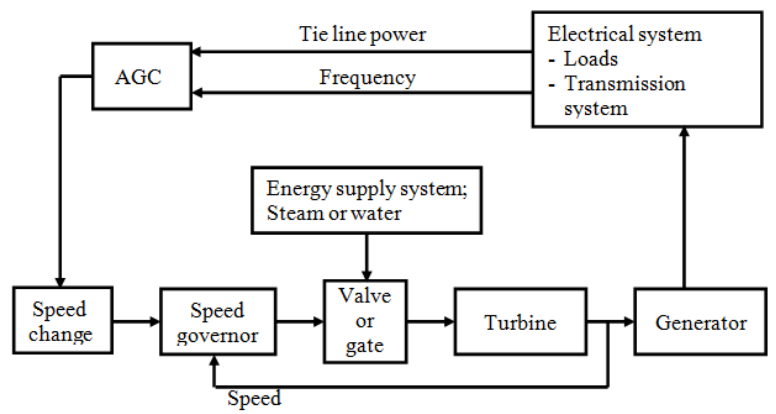

Fig 1: Functional block diagram of power generation and control system

A steam turbine converts stored energy of high pressure and high temperature steam into rotating energy, which is in turn converted into electrical energy by the generator. The heat source of the boiler supplying the steam may be a nuclear reactor or a furnace fired by fossil fuel (coal, oil, or gas).

Steam turbines with a variety of configuration have been built depending on unit size and steam conditions. They normally consist of two or more turbine sections or cylinders couples in series. Each turbine section consists of a set of moving blades attached to rotor and a set of stationary vans. The moving blades are called buckets. The stationary vans, referred to a nozzle sections, from nozzles or passages in which steam is accelerated to high velocity. The kinetic energy of this high velocity steam is converted into shaft torque by the buckets.

A turbine with multiple sections may be either tandemcompound or cross-compound. In a tandem-compound turbine, the sections are all on one shaft, with a single generator. In contrast, a cross-compound turbine consist of two shafts, each connected to a generator and driven by one or more turbine sections; however, it's designed and operated as a single unit with one set of controls. The crosscompounding results in grater capacity and improved efficiency but is more expensive. It is seldom used now; most new units placed in service in recent have been of the tandem-compound design [1].

\section{POLE PLACEMENT TECHNIQUE}

In the conventional approach to the design of a single-inputsingle-output control system, the controller design (regulator) such that the dominant closed-loop poles have a desired damping ratio $\xi$ and an undamped natural frequency $\omega_{n}$.

The present pole-placement technique specifies all closedloop poles. (There is a cost associated with placing all closedloop poles, however, because placing all closed-loop poles requires successful measurement of all state variables). Such a system where the reference input always zero is called a regulator system. A block diagram for this system is as shown in Figure 2.

The problem of placing the regulator poles (closed-loop poles) at the desired location is called pole-placement problem, and this can be done if and only if the system is completely state controllable $[4,5 \& 6]$.

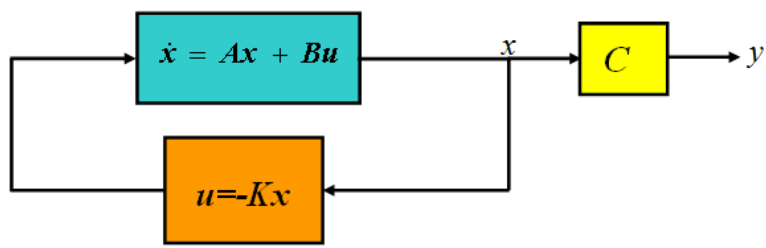

Fig 2: Pole Placement Block Diagram 


\section{STEAM TURBINE MODELING}

As mentioned earlier different types of turbines have different characteristics. This source of mechanical power can be a hydraulic turbine, steam turbine and others. Six types of steam turbine models are discussed in an IEEE transaction report [7].

The model for a single reheat tandem-compound steam turbine shown in Figure 3 can be used in the thesis. The model for turbine associates the changes in mechanical power $\Delta \mathrm{P}_{\mathrm{M}}$ with the changes in steam valve position $\Delta \mathrm{P}_{\mathrm{GV}}$.

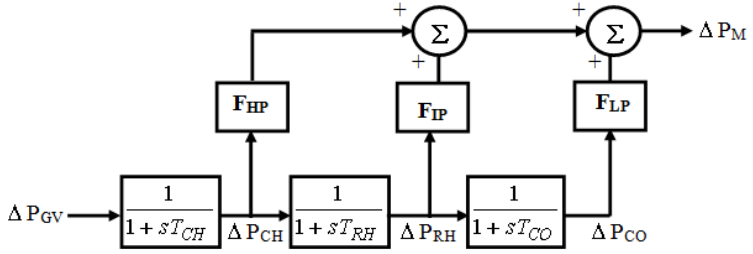

Fig 3: Single reheater tandem-compound steam turbine model

Hence the transfer function is

$\frac{\Delta P_{M}(s)}{\Delta P_{G V}(s)}=\left[\frac{F_{L P}}{T_{C H} T_{R H} T_{C O} s^{3}+\left(T_{C H} T_{R H}+\left(T_{C H}+T_{R H}\right) T_{C O}\right) s^{2}+\left(T_{C H}+T_{R H}+T_{C O}\right) s+1}\right.$

$\left.+\frac{F_{H P}}{T_{C H} s+1}+\frac{F_{I P}}{T_{C H} T_{R H} s^{2}+\left(T_{C H}+T_{R H}\right) s+1}\right]$

In the vector-matrix form, the turbine can be given as follows:

$$
\frac{d}{d t}\left[\begin{array}{l}
\Delta P_{C H} \\
\Delta P_{R H} \\
\Delta P_{C O}
\end{array}\right]=\left[\begin{array}{ccc}
\frac{-1}{T_{C H}} & 0 & 0 \\
\frac{1}{T_{R H}} & \frac{-1}{T_{R H}} & 0 \\
0 & \frac{1}{T_{C O}} & \frac{-1}{T_{C O}}
\end{array}\right]\left[\begin{array}{c}
\Delta P_{C H} \\
\Delta P_{R H} \\
\Delta P_{C O}
\end{array}\right]+\left[\begin{array}{c}
\frac{1}{T_{C H}} \\
0 \\
0
\end{array}\right]\left[\Delta P_{G V}\right]
$$

\section{STEAM TURBINE SPEED GOVERNING SYSTEM}

The prime mover governing system provides a means of controlling real power and frequency. The relationship between the basic elements associated with power generation and control is shown in Figure 4. Stability of the turbine depends on the way the speed/load-control system positions the control valves so that a sustained oscillation of the turbine speed or of the power output as produced by the speed/loadcontrol system does not exceed a specified value during operation under steady-state load demand or following a change to a new steady-state load demand. This steady-state load demand is being expressed in terms of a range of values in a control band. This band is called steady-state loadcontrol band $\Delta \mathrm{P}_{\mathrm{b}}[8]$.

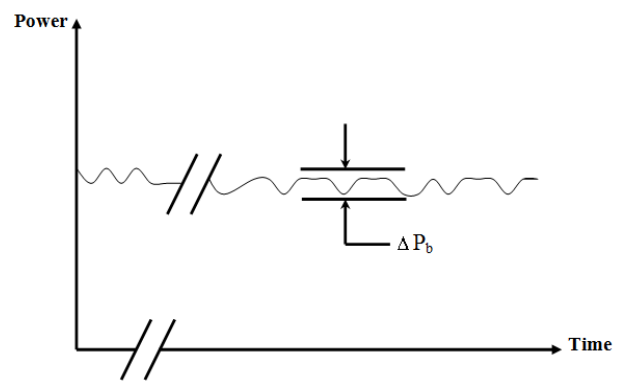

Fig 4: Steady-state load-control band

A basic characteristic of a governor is shown in Figure 5

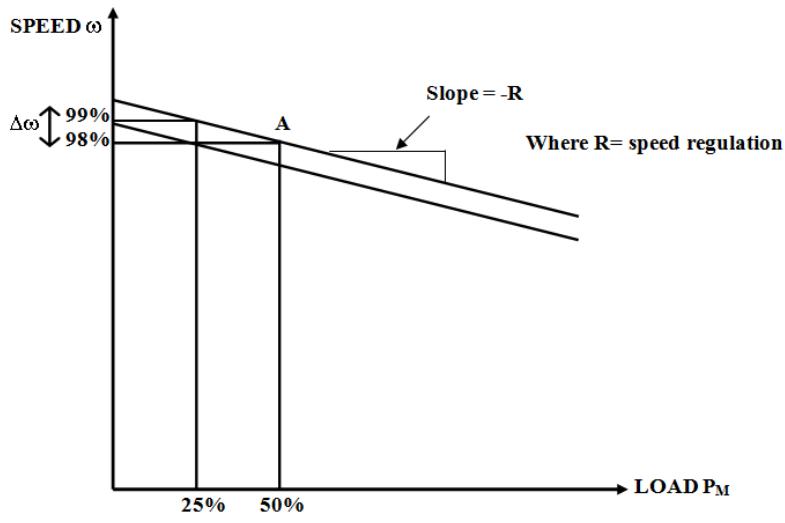

Fig 5: Governor Characteristic

From Figure 5, there is a definite relationship between the turbine speed and the load being carried by the turbine for a given setting. The increase in load will lead to a decrease in speed. The example given in Figure 5 shows that if the initial operating point is at $\mathrm{A}$ and the load is dropped to $25 \%$, the speed will increase. In order to maintain the speed at A, the governor setting by changing the spring tension in the fly-ball type of governor will be resorted to and the characteristic of the governor will be indicated by the dotted line as shown in Figure 5. [1]

Figure 5 illustrates the ideal characteristic of the governor whereas the actual characteristic departs from the ideal one due to valve openings at different loadings.

Figure 5 shows the time response of a generating unit, with an isochronous governor (the adjective isochronous means constant speed), when subjected to an increase in load. The increase in electrical power causes the frequency to decay at a rate determined by the inertia of rotor. As the speed drops, the turbine mechanical power begins to increase. This in turn causes a reduction in the rate of decrease of speed, and then an increase in speed when the turbine power is in excess of the load power. The speed will ultimately return to its reference value and the steady state turbine power increases by an amount equal to the additional load.

In contrast to the excitation system, the governing system is a relatively slow response system because of the slow reaction of mechanic operation of turbine machine [1]. 


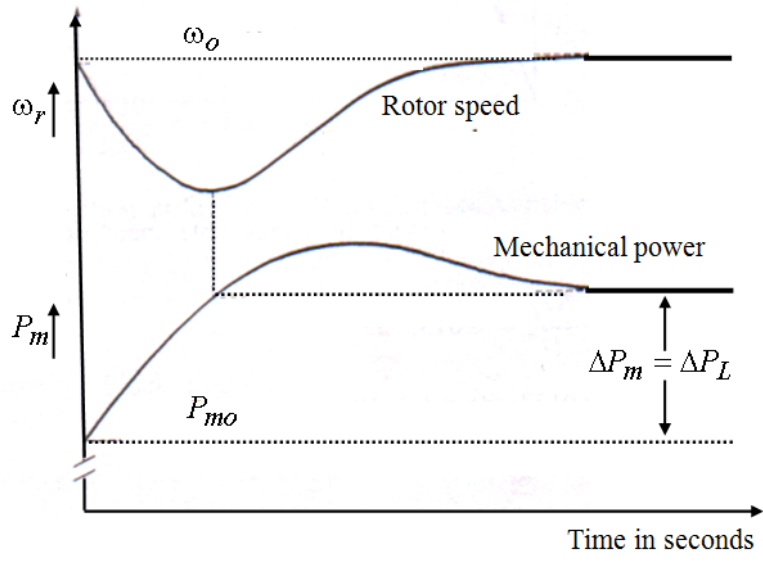

Fig 6: Response of generating unit with isochronous governor

\section{MECHANICAL-HYDRAULIC CONTROL}

A typical mechanical-hydraulic speed-governing system consist of a speed governor, a speed relay, a hydraulic servomotor, and governor-controlled valves which are functionally related as shown in Figure 7.

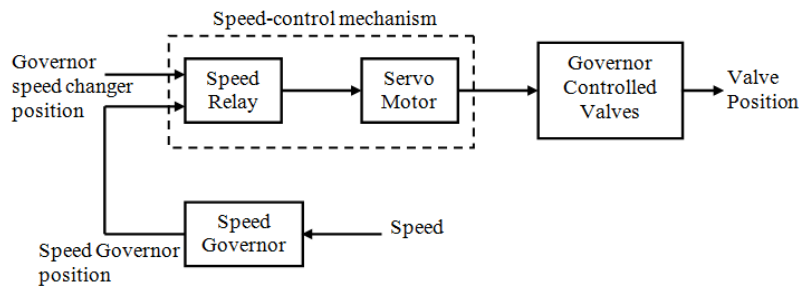

Fig 7: Mechanical-Hydraulic speed-governing system for steam turbines

The block diagram of Figure 8 shows an approximate mathematical model. The speed governor produces a position which is assumed to be a linear, instantaneous indication of speed and is represented by a gain $\mathrm{K}_{\mathrm{G}}$ which is reciprocal of regulation or droop. The signal $\Delta \mathrm{P}_{\text {ref }}$, is obtained from the governor speed changer of Figure 1, and is determined by the automatic generation control system. It represents a composite load and speed reference and is assumed constant over the interval of a stability study [7].

The speed relay is represented as an integrator with time constant $T_{S R}$ and direct feedback.

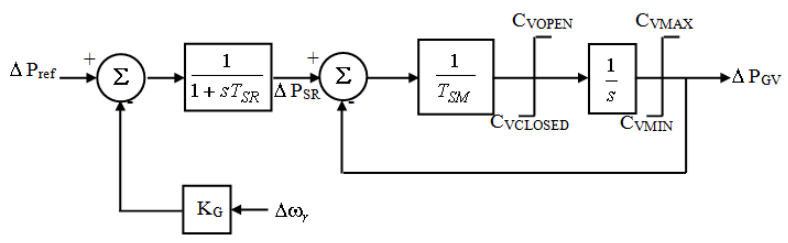

Fig 8: Mathematical representation of the speed-governing system

The servomotor is represented by an integrator with time constant $T_{S M}$ and direct feedback.

The servomotor moves the valves and is physically large, particularly on large units. Rate limiting of the servomotor may occur for large, rapid speed deviation, and rate limits are shown at the input to the integrator representing the servomotor. Position limits are also indicated and may correspond to wide-open valves or the setting of a load limiter [7].

In power system studies, nonlinearities in the speed-control mechanism are normally neglected.

In the vector-matrix form, the speed governing system can be given as follows:

$$
\frac{d}{d t}\left[\begin{array}{c}
\Delta P_{G V} \\
\Delta P_{S R}
\end{array}\right]=\left[\begin{array}{cc}
\frac{-1}{T_{S M}} & \frac{1}{T_{S M}} \\
0 & \frac{-1}{T_{S R}}
\end{array}\right]\left[\left[\begin{array}{c}
\Delta P_{G V} \\
\Delta P_{S R}
\end{array}\right]\right]+\left[\begin{array}{cc}
0 & 0 \\
\frac{1}{T_{S R}} & \frac{-K_{G}}{T_{S R}}
\end{array}\right]\left[\begin{array}{c}
\Delta P_{r e f} \\
\Delta \omega_{r}
\end{array}\right]
$$

Depending on the previous derivations, the complete mode for the governor- turbine can be given as below in Figure 9.

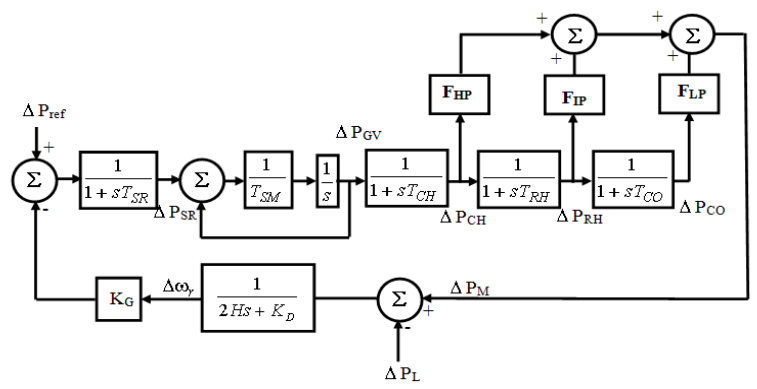

Fig 9: Governor-turbine model

In the vector-matrix form, the governor-turbine system can be given as follows:

$$
\frac{d}{d t}\left[\begin{array}{c}
\Delta \omega_{r} \\
\Delta P_{S R} \\
\Delta P_{G V} \\
\Delta P_{C H} \\
\Delta P_{R H} \\
\Delta P_{C O}
\end{array}\right]=\left[\begin{array}{cccccc}
\frac{-K_{D}}{2 H} & 0 & 0 & \frac{F_{H P}}{2 H} & \frac{F_{I P}}{2 H} & \frac{F_{L P}}{2 H} \\
\frac{-K_{G}}{T_{S R}} & \frac{-1}{T_{S R}} & 0 & 0 & 0 & 0 \\
0 & \frac{1}{T_{S M}} & \frac{-1}{T_{S M}} & 0 & 0 & 0 \\
0 & 0 & \frac{1}{T_{C H}} & \frac{-1}{T_{C H}} & 0 & 0 \\
0 & 0 & 0 & \frac{1}{T_{R H}} & \frac{-1}{T_{R H}} & 0 \\
0 & 0 & 0 & 0 & \frac{1}{T_{C O}} & \frac{-1}{T_{C O}}
\end{array}\right]\left[\begin{array}{c}
\Delta \omega_{r} \\
\Delta P_{S R} \\
\Delta P_{G V} \\
\Delta P_{C H} \\
\Delta P_{R H} \\
\Delta P_{C O}
\end{array}\right]+\left[\begin{array}{cc}
0 & \frac{-1}{2 H} \\
\frac{1}{T_{S R}} & 0 \\
0 & 0 \\
0 & 0 \\
0 & 0 \\
0 & 0
\end{array}\right]\left[\begin{array}{c}
\Delta P_{r e f} \\
\Delta P_{L}
\end{array}\right]
$$

\section{PERFORMANCE EVALUATION OF DESIGN CONVENTIONAL GOVERNOR}

It can be seen that from (3), which represent the governorturbine model, as shown in Figure 8, the input will be taken to be as the $\Delta P_{l}$, which can be changed as $6 \%, 8 \%, 10 \%$ and $15 \%$ and assuming $\Delta P_{\text {ref. }}=0$. The output will be chosen to be the changes in the mechanical power $\Delta P_{m}$ and the frequency response $\Delta \omega_{\mathrm{r}}$ as shown in Figure 10. Table 1 and Table 2 gives the time domain specifications evaluated for $6 \%, 8 \%$, $10 \%$ and $15 \%$ load changes 
TABLE 1 TIME DOMAIN SPECIFICATION FOR CONVENTIONAL GOVERNOR FROM $\triangle \mathrm{P}_{\mathrm{m}}$ GRAPH

\begin{tabular}{|c|c|c|c|c|c|}
\hline $\begin{array}{c}\% \\
\Delta P_{L}\end{array}$ & $\mathrm{t}_{\mathrm{s}}$ & $\mathrm{t}_{\mathrm{r}}$ & $\begin{array}{c}\text { Peak } \\
\text { Amplitude }\end{array}$ & $\mathrm{t}_{\mathrm{p}}$ & $\% \mathrm{M}_{\mathrm{P}}$ \\
\hline 6 & 9 & 1.15 & 0.608 & 3.36 & 44.8 \\
\hline 8 & 9 & 1.15 & 0.811 & 3.36 & 44.8 \\
\hline 10 & 9 & 1.15 & 1.01 & 3.36 & 44.8 \\
\hline 15 & 9 & 1.15 & 1.45 & 3.36 & 44.8 \\
\hline
\end{tabular}

TABLE 2 TIME DOMAIN SPECIFICATION FOR CONVENTIONAL GOVERNOR FROM $\Delta \omega_{\mathrm{r}}$ GRAPH

\begin{tabular}{|c|c|c|c|c|c|}
\hline $\begin{array}{c}\% \\
\Delta P_{L}\end{array}$ & $\mathrm{t}_{\mathrm{s}}$ & $\mathrm{t}_{\mathrm{r}}$ & $\begin{array}{c}\text { Peak } \\
\text { Amplitude }\end{array}$ & $\mathrm{t}_{\mathrm{p}}$ & $\% \mathrm{M}_{\mathrm{P}}$ \\
\hline 6 & 10.9 & 0.256 & -0.0715 & 1.92 & 275 \\
\hline 8 & 10.9 & 0.256 & -0.0953 & 1.92 & 275 \\
\hline 10 & 10.9 & 0.256 & -0.119 & 1.92 & 275 \\
\hline 15 & 10.9 & 0.256 & -0.17 & 1.92 & 275 \\
\hline
\end{tabular}

Governor when $6 \%, 8 \%, 10 \%$ and $15 \%$ change in Delta PL

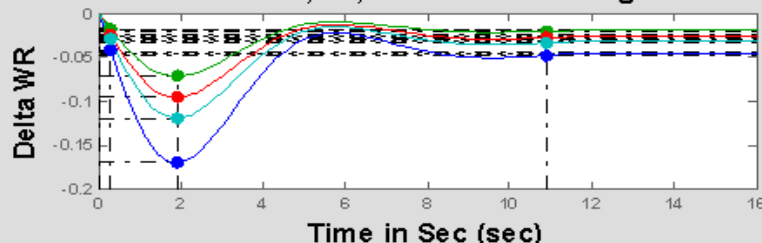

Governor when $6 \%, 8 \%, 10 \%$ and $15 \%$ change in Delta PL

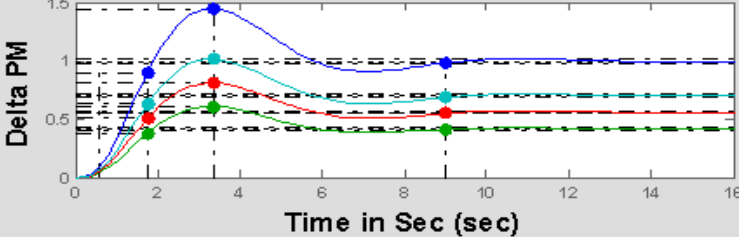

Fig 10: $\Delta \omega_{r}$ and $\Delta P_{m}$ change for $6 \%, 8 \%, 10 \% \& 15 \%$ the load changes

\section{PERFORMANCE EVALUATION OF DESIGN POLE PLACEMENT AS GOVERNOR}

For the same block diagram shown in Figure 9, the governorturbine (plant) mathematical model without a controller was given by equation 3 .

For this model $\xi$ was chosen arbitrary to be 0.85 , and $\omega_{n}$ was chosen to be 0.5536 , and accordingly the roots will be ($0.4706+0.291609 \mathrm{i},-0.4706-0.291609 \mathrm{i}, 3.7648+2.332872 \mathrm{i}$, 3.7648-2.332872i, $5.6472+3.499308 \mathrm{i}$, $-5.6472$ $3.499308 i$ ), depending on these roots the values of the time domain specifications evaluated are given in Table 3 and Table 4. Figure 11 shows the plotting of the $\Delta \omega_{r}$ and $\Delta \mathrm{P}_{\mathrm{m}}$ versus $\mathrm{t}$ for $6 \%, 8 \%$ and $15 \%$ of load changes. Figure 12 shows all the changes on same graph.
TABLE 3 TIME DOMAIN SPECIFICATION FOR POLE PLACEMENT GOVERNOR FROM $\triangle \mathrm{P}_{\mathrm{m}}$ GRAPH

\begin{tabular}{|c|c|c|c|c|c|}
\hline $\begin{array}{c}\% \\
\Delta P_{L}\end{array}$ & $\mathrm{t}_{\mathrm{s}}$ & $\mathrm{t}_{\mathrm{r}}$ & $\begin{array}{c}\text { Peak } \\
\text { Amplitude }\end{array}$ & $\mathrm{t}_{\mathrm{p}}$ & $\% \mathrm{M}_{\mathrm{P}}$ \\
\hline 6 & 8.08 & 2.82 & 0.202 & 6.72 & 2.44 \\
\hline 8 & 8.08 & 2.82 & 0.27 & 6.72 & 2.44 \\
\hline 10 & 8.08 & 2.82 & 0.337 & 6.72 & 2.44 \\
\hline 15 & 8.08 & 2.82 & 0.481 & 6.72 & 2.44 \\
\hline
\end{tabular}

TABLE 4 TIME DOMAIN SPECIFICATION FOR POLE PLACEMENT GOVERNOR FROM $\Delta \omega_{\mathrm{r}}$ GRAPH

\begin{tabular}{|c|c|c|c|c|c|}
\hline $\begin{array}{c}\% \\
\Delta P_{L}\end{array}$ & $\mathrm{t}_{\mathrm{s}}$ & $\mathrm{t}_{\mathrm{r}}$ & $\begin{array}{c}\text { Peak } \\
\text { Amplitude }\end{array}$ & $\mathrm{t}_{\mathrm{p}}$ & $\% \mathrm{M}_{\mathrm{P}}$ \\
\hline 6 & 9.44 & 0.138 & -0.018 & 1.95 & 100 \\
\hline 8 & 9.44 & 0.138 & -0.024 & 1.95 & 100 \\
\hline 10 & 9.44 & 0.138 & -0.03 & 1.95 & 100 \\
\hline 15 & 9.44 & 0.138 & -0.0428 & 1.95 & 100 \\
\hline
\end{tabular}

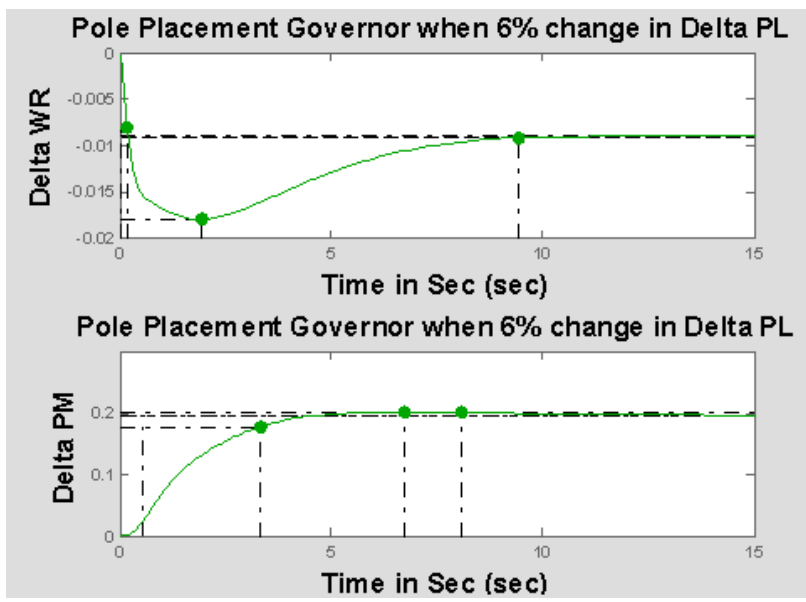

Fig 11.a: $\Delta \omega_{r}$ and $\Delta P_{m}$ change for $6 \%$ load change using Pole Placement governor

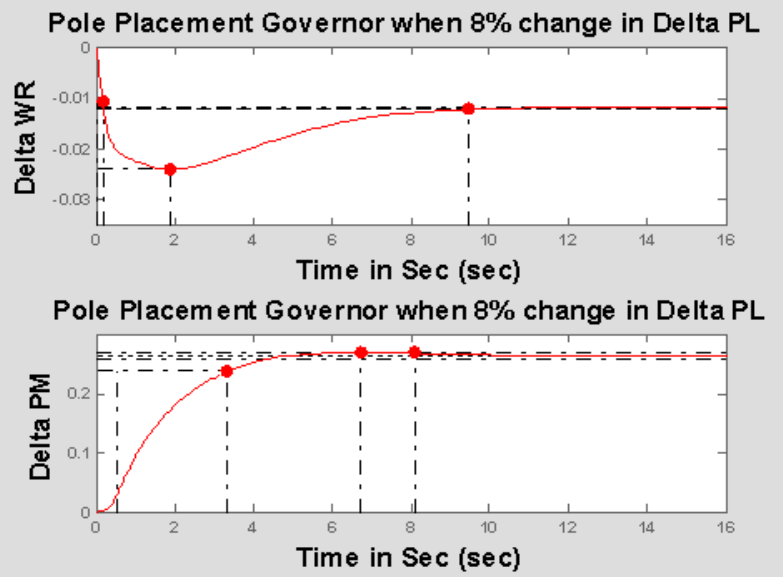

Fig 11.b: $\Delta \omega_{r}$ and $\Delta \mathbf{P}_{\mathrm{m}}$ change for $8 \%$ load change using Pole Placement governor 


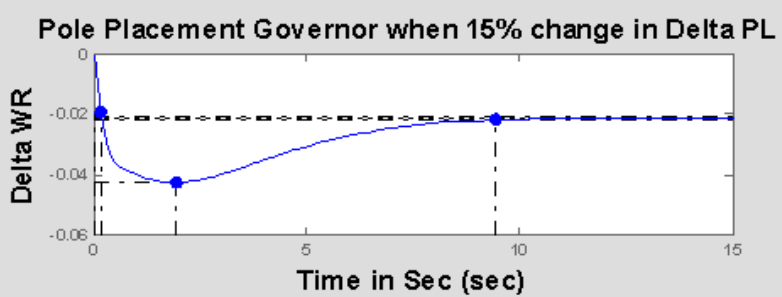

Pole Placement Governor when $15 \%$ change in Delta PL

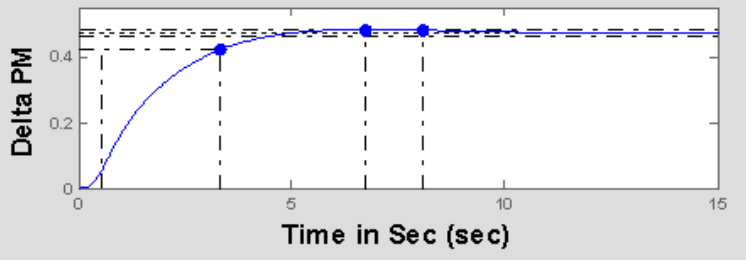

Fig 11.c: $\Delta \omega_{r}$ and $\Delta P_{m}$ change for $15 \%$ load change using Pole Placement governor
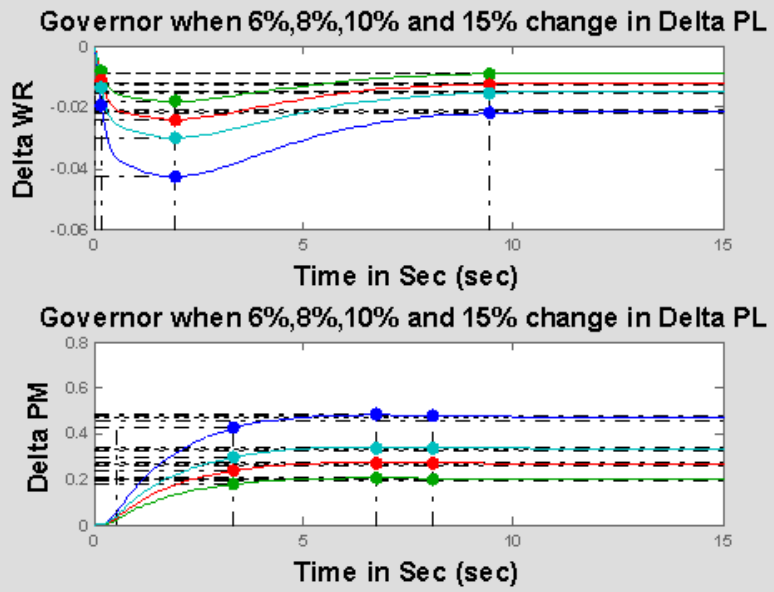

Fig 12: $\Delta \omega_{r}$ and $\Delta P_{m}$ change for $6 \%, 8 \%, 10 \&$ and $15 \%$ load changes using Pole Placement governor

\section{CONCLUSIONS}

The main conclusions from the work are:

a. In this work a controller based on a pole placement technique designed to control the turbine speed. This technique which depends on the pole placement gives best damping torque with comparison with the conventional techniques which leads to improving the stability of the whole system.

b. Applying the pole placement on the turbine as a governor gave the best results for the time domain specifications over the conventional one. From these results the settling time in which for the conventional governor is about 10.9 sec and using the pole placement the settling time reduced to about $9.44 \mathrm{sec}$.

\section{REFERENCES}

[1] P.Kundor: power system stability and control, McGrawHill, Inc, 1994

[2] Goran Andersson: Dynamics and Control of Electric Power Systems, ETH Zurich, March 2004.

[3] H. Saadat, Power System Analysis, McGrawHillInc., 1999.

[4] Katsuhiko Ogata: System Dynamics; Prentice Hall International, Inc. Third Edition 1998.

[5] Katsuhiko Ogata: Modern Control Engineering; Prentice Hall International, Inc. Fourth Edition 2002.

[6] Richard C. Dorf and Robert H. Bishop: Modern Control Systems; Pearson Prentice Hall, 2005

[7] IEEE Committee," Dynamics Models for Steam and Hydro Turbines in Power System Studies, ,. IEEE Trans. PAS., pp1904-1915, December 1973.

[8] Bok Eng Law: Simulation of the Transient Response of Synchronous Machines, The University of Queensland, October 2001.

\section{LIST OF SYMBOLS \\ $\mathrm{T}_{\mathrm{SR}}=\quad$ Speed Relay time constant \\ $\mathrm{T}_{\mathrm{SM}}=\quad$ Servomotor time constant \\ $\mathrm{T}_{\mathrm{CH}}=\quad$ Chest time constant \\ $\mathrm{T}_{\mathrm{RH}}=\quad$ Reheater time constant \\ $\mathrm{T}_{\mathrm{CO}}=\quad$ Cross Over time constant \\ $\mathrm{F}_{\mathrm{HP}}=\quad$ High Pressure fraction \\ $\mathrm{F}_{\mathrm{IP}}=\quad$ Inermediate Pressure fraction \\ $\mathrm{F}_{\mathrm{LP}}=\quad$ Low Pressure fraction \\ $H=\quad$ Inertia constant in MW.s/MVA \\ $\Delta \omega_{r}=\quad$ Speed deviation in pu $=\left(\omega_{r}-\omega_{o}\right) / \omega_{o}$ \\ $\Delta \delta=\quad$ Rotor angle deviation in elect.rad \\ $\omega_{o}=\quad$ Rated speed in elect.rad $/ \mathrm{s}=2 \pi f_{o}=314$ \\ $\mathrm{K}_{\mathrm{G}}=\quad$ reciprocal of regulation or droop}

\section{APPENDIX}

The power system data are as follows:

$\mathrm{M}=7, \quad \mathrm{FHP}=0.3, \quad \mathrm{FIP}=0.4, \quad \mathrm{FLP}=0.4, \quad \mathrm{KG}=20, \quad \mathrm{TSR}=0.1$, $\mathrm{TSM}=0.3, \mathrm{TCH}=0.3,=7,=0.4, \mathrm{H}=3.5 \mathrm{MW} . \mathrm{s} / \mathrm{MVA}$ 